\title{
Estimating variance components and breeding values for number of oocytes and number of embryos in dairy cattle using a single-step genomic evaluation
}

\author{
M. A. M. C. Cornelissen, ${ }^{*}$ E. Mullaart, $†$ C. Van der Linde, $\nmid$ and H. A. Mulder*1 \\ *Wageningen University \& Research Animal Breeding and Genomics, PO Box 338, 6700 AH Wageningen, the Netherlands \\ †CRV BV, Wassenaarweg 20, 6843 NW Arnhem, the Netherlands
}

\begin{abstract}
Reproductive technologies such as multiple ovulation and embryo transfer (MOET) and ovum pick-up (OPU) accelerate genetic improvement in dairy breeding schemes. To enhance the efficiency of embryo production, breeding values for traits such as number of oocytes (NoO) and number of MOET embryos (NoM) can help in selection of donors with high MOET or OPU efficiency. The aim of this study was therefore to estimate variance components and (genomic) breeding values for $\mathrm{NoO}$ and NoM based on Dutch Holstein data. Furthermore, a 10-fold cross-validation was carried out to assess the accuracy of pedigree and genomic breeding values for $\mathrm{NoO}$ and NoM. For NoO, 40,734 OPU sessions between 1993 and 2015 were analyzed. These OPU sessions originated from 2,543 donors, from which 1,144 were genotyped. For NoM, 35,695 sessions between 1994 and 2015 were analyzed. These MOET sessions originated from 13,868 donors, from which 3,716 were genotyped. Analyses were done using only pedigree information and using a single-step genomic BLUP (ssGBLUP) approach combining genomic information and pedigree information. Heritabilities were very similar based on pedigree information or based on ssGBLUP [i.e., 0.32 (standard error $=0.03$ ) for $\mathrm{NoO}$ and 0.21 (standard error $=0.01$ ) for NoM with pedigree, 0.31 (standard error $=0.03$ ) for $\mathrm{NoO}$, and 0.22 (standard error $=0.01$ ) for NoM with ssGBLUP] For animals without their own information as mimicked in the cross-validation, the accuracy of pedigree-based breeding values was 0.46 for $\mathrm{NoO}$ and NoM. The accuracies of genomic breeding values from ssGBLUP were 0.54 for $\mathrm{NoO}$ and 0.52 for NoM. These results show that including genomic information increases the accuracies. These moderate accuracies in combination
\end{abstract}

Received September 30, 2016.

Accepted February 6, 2017.

${ }^{1}$ Corresponding author: han.mulder@wur.nl with a large genetic variance show good opportunities for selection of potential bull dams.

Key words: ovum pick-up, multiple ovulation and embryo transfer, accuracy, genomic breeding value

\section{INTRODUCTION}

Nowadays, reproductive technologies such as ovum pick-up (OPU) and multiple ovulation and embryo transfer (MOET) are broadly used in cattle breeding (Betteridge, 2003). Although both technologies are used to produce embryos, the major difference between them is the place of maturation and fertilization of the oocytes. With MOET, the maturation and fertilization of the oocytes and the embryo growth until $\mathrm{d} 7$ is in vivo, but with OPU, it is in vitro (Pieterse et al., 1988; Merton et al., 2003).

Worldwide, 1,531,609 oocytes were collected using OPU and 339,969 embryos were transferred in dairy cattle in 2013 (IETS, 2014). The quantity of embryos collected after MOET or oocytes collected by OPU in one session depends on several factors. Nongenetic factors such as hormone-related factors, technician, age of the animal, and interval between sessions influence the quantity of embryos and oocytes collected with MOET or OPU (Merton et al., 2003).

Although the main focus in most studies was on nongenetic factors, some research has also been done on genetic factors. For number of oocytes $(\mathrm{NoO})$ collected with OPU, a heritability of 0.25 was reported (Merton et al., 2009). For number of MOET (NoM) embryos, a heritability of 0.17 was reported (Jaton et al., 2016). The MOET and OPU can accelerate genetic improvement due to higher selection intensity when selecting bull dams, because more offspring per bull dam can be produced and therefore fewer dams can be selected compared with classical breeding (Hanenberg and van Wagtendonk-de Leeuw, 1997; Merton et al., 2003). With the introduction of genomic selection in dairy cattle, MOET and OPU can further accelerate genetic improvement, because with genomic selection 
relatively accurate breeding values can be estimated for animals at a relatively young age, even at birth or at embryo level (Schaeffer, 2006).

Including $\mathrm{NoO}$ and $\mathrm{NoM}$ in selection decisions can improve the efficiency of embryo production programs by selecting donors with a high MOET or OPU efficiency (Merton et al., 2009). The aim of this study was therefore to estimate variance components and (genomic) EBV for NoO and NoM based on Dutch Holsteins. The second aim was to assess the accuracy of pedigree and genomic breeding values for $\mathrm{NoO}$ and NoM using cross-validation.

\section{MATERIALS AND METHODS}

\section{Data}

In this study, NoO and NoM were the 2 traits analyzed, and for each trait a different data set was used (data provided by CRV, Arnhem, the Netherlands). For OPU, immature oocytes were collected once or twice per week at 5 nucleus herds in the Netherlands. The OPU sessions were performed in teams of 2 persons: the technician, responsible for the manipulation of the ultrasound probe and the ovary, and the assistant, responsible for the punctures of the follicles (Merton et al., 2009). The information collected from the OPU sessions were NoO collected per OPU session, the quality of the oocytes, OPU technicians, location of OPU, date of OPU, frequency of OPU, parity, and lactation stage of the cow. This data file contained information from OPU sessions from January 1993 to April 2015. Data were collected for 56,058 OPU sessions from 4,273 animals. Data were excluded if OPU sessions were not at nucleus farms (too few observations per location), if OPU technicians had less than 10 observations, and if OPU intervals were of $1,2,6$, or $8 \mathrm{~d}$, because usual intervals were of 3,4 , or $7 \mathrm{~d}$. After data editing, the data file contained 40,734 OPU sessions and 2,543 animals with an average of 17.8 sessions/donor. The pedigree of the 2,543 animals with OPU data contained 11,807 animals and 27 generations in total. From the 2,543 animals with OPU data, 2,049 animals did not have progeny with OPU observations. Dams had between 1 and 49 offspring with OPU observations and sires had between 1 and 59 offspring with OPU observations.

For MOET, multiple oocytes were recruited for ovulation after hormone stimulation (superovulation). The ovulated ova were fertilized by AI and the fertilized ova developed into embryos. The ova migrated from the oviducts into the uterus. Approximately $7 \mathrm{~d}$ after insemination, the uterus was flushed (Merton et al., 2003; van Wagtendonk-de Leeuw, 2006). The information from the MOET sessions included in the data file were NoM, MOET technician, location, protocol, and date of session. This data file contained information from MOET sessions from June 1989 to August 2015. Data were collected for 43,810 MOET sessions from 18,822 animals. In the data editing, records were excluded when locations or technicians had less than 10 sessions, when sessions were performed before 1994 or without superovulation and when non-Holstein Friesian animals were used. After data editing, the data file contained 35,695 MOET sessions and 13,868 animals with an average of 3.0 sessions/animal. The pedigree of the 13,868 animals with MOET data contained 41,231 animals and 27 generations in total. From these 13,868 animals, 10,383 animals did not have progeny with MOET observations. Dams had between 1 and 57 offspring with MOET observations and sires had between 1 and 370 offspring with MOET observations. Summary statistics are shown in Table 1.

\section{Genomic Data}

Part of the animals with OPU or MOET data were genotyped using the Illumina 10 or 50K SNP chip. The animals genotyped with a 10K SNP chip were imputed to 50K SNP. For imputation, a combination of Phasebook software (Druet and Georges, 2010) and Beagle (Browning and Browning, 2007) was used (Mulder et al., 2012). For OPU, 1,144 animals of the 2,543 animals with observations were genotyped. From these 1,144 animals, 890 animals did not have progeny with OPU observations. For MOET, 3,716 of the 13,868 animals with observations were genotyped. From these 3,716

Table 1. Summary statistics of number of oocytes with and without log-transformation $\left(\mathrm{NoO}\right.$ and $\left.\mathrm{NoO}_{\log }\right)$ and number of multiple ovulation and embryo transfer embryos with and without Anscombe transformation (NoM and $\mathrm{NoM}_{\text {Ans }}$ ) after data editing

\begin{tabular}{lcccc}
\hline Trait & No. of records & Mean & SD & Minimum-maximum \\
\hline $\mathrm{NoO}$ & 40,734 & 7.716 & 5.283 & $0-81$ \\
$\mathrm{NoO}$ & 40,734 & 0.867 & 0.260 & $0-1.914$ \\
$\mathrm{NoM}$ & 35,695 & 9.273 & 7.260 & $0-97$ \\
$\mathrm{NoM}_{\text {Ans }}$ & 35,695 & 2.872 & 1.184 & $0.612-9.868$ \\
\hline
\end{tabular}


animals, 2,729 animals did not have progeny with MOET observations. Both for OPU and MOET, genotypes of animals without phenotypes, but related to phenotyped and genotyped animals, were also used to construct the genomic relationship matrix. In total, genotypes of 1,991 animals were used for OPU $(1,269$ females and 722 males) and genotypes of 5,690 animals were used for MOET (4,044 females and 1,646 males).

\section{Data Transformation}

The traits NoO and NoM did not follow a normal distribution. Two different transformations were used. The trait $\mathrm{NoO}$ approximated a normal distribution best after log-transformation using visual inspection (SPSS Inc., 2007). The trait $\mathrm{NoO}$ was transformed as follows: $\mathrm{NoO}_{\log }=\log (\mathrm{NoO}+1)$, where $\mathrm{NoO}_{\log }$ is the log-transformed NoO. For NoM, the normal distribution was visually best approximated by the Anscombe transformation (SPSS Inc., 2007). The trait NoM was transformed as follows:

$$
\mathrm{NoM}_{\mathrm{Ans}}=\sqrt{\mathrm{NoM}+\frac{3}{8}},
$$

where $\mathrm{NoM}_{\text {Ans }}$ is the Anscombe-transformed NoM (Anscombe, 1948).

\section{Variance Components and Heritability}

Univariate models were used to estimate variance components with REML using ASReml software (Gilmour et al., 2009). A Wald $F$ statistic was used to test whether fixed effects were significant. Fixed effects that were significant are listed in Table 2 together with the number of levels in the edited data set. Furthermore, the random additive genetic and permanent environment effects were included, because most donors had repeated measurements. The general model used was $\mathbf{y}$ $=\mathbf{X} \boldsymbol{\beta}+\mathbf{Z} \mathbf{a}+\mathbf{W} \mathbf{p}+\mathbf{e}$, where $\mathbf{y}$ is a vector with individual records for $\mathrm{NoO}_{\log }$ or $\mathrm{NoM}_{\text {Ans }} ; \mathbf{X}, \mathbf{Z}$, and $\mathbf{W}$ are incidence matrices; $\boldsymbol{\beta}$ is a vector of fixed effects (Table $2)$; $\mathbf{a}$ is a vector of random additive genetic effects; $\mathbf{p}$ is a vector of random permanent environmental effects of the donor; and e is a vector of random residuals. The permanent environmental effects and residuals were assumed to be normally distributed $\mathbf{p} \sim N\left(0, \mathbf{I} \sigma_{\mathrm{PE}}^{2}\right), \mathbf{e} \sim N\left(0, \mathbf{I} \sigma_{\mathrm{e}}^{2}\right)$, where $\mathbf{I}$ is an identity matrix, $\sigma_{\mathrm{PE}}^{2}$ is the permanent environmental variance, and $\sigma_{\mathrm{e}}^{2}$ is the residual variance. When using only pedigree information, the additive genetic effects were assumed normally distributed with $\mathbf{a} \sim N\left(0, \mathbf{A} \sigma_{\mathrm{a}}^{2}\right)$, where $\mathbf{A}$ is a matrix of additive genetic relationships between individuals based on pedigree and $\sigma_{\mathrm{a}}^{2}$ is the additive genetic variance. When combining genomic and pedigree information, a single-step genomic BLUP approach (ssGBLUP) was used (Aguilar et al., 2010). In this case the additive genetic effects were assumed to be normally distributed with $\mathbf{a} \sim N\left(0, \mathbf{H} \sigma_{\mathrm{a}}^{2}\right)$, where $\mathbf{H}$ is a matrix of additive genetic relationships between individuals based on pedigree combined with genomic relationships. Because for the mixed models $\mathbf{H}^{-1}$ is needed rather than $\mathbf{H}$ (Aguilar et al., 2010; Christensen and Lund, 2010), $\mathbf{H}^{-1}$ was constructed directly using

$$
\mathbf{H}^{-1}=\mathbf{A}^{-1}+\left[\begin{array}{lc}
0 & 0 \\
0 & \left(\left(\lambda \mathbf{G}+(1-\lambda) \mathbf{A}_{22}\right)^{-1}-\mathbf{A}_{22}^{-1}\right)
\end{array}\right],
$$

Table 2. Description of fixed effects used in the models to estimate genetic parameters and breeding values for log-transformed number of oocytes $\left(\mathrm{NoO}_{\log }\right)$ and Anscombe-transformed number of multiple ovulation and embryo transfer embryos $\left(\mathrm{NoM}_{\text {Ans }}\right)$

\begin{tabular}{lcc}
\hline Effect & No. of classes for $\mathrm{NoO}_{\log }$ & No. of classes for NoM $_{\text {Ans }}$ \\
\hline Technician & 17 & 25 \\
Assistant & 26 & - \\
Parity & 3 & - \\
Age (mo) & - & - \\
Technician $\times$ assistant & 53 & - \\
Interval & 5 & 487 \\
Location & 12 & 12 \\
Month & 23 & 22 \\
Year & 276 & - \\
Month $\times$ year & 200 & - \\
Session number & 2 & - \\
Pregnancy status & 6 & 15 \\
Parity $\times$ pregnancy status & - & \\
Protocol & &
\end{tabular}

${ }^{1}$ Within a column, fixed effects indicated with a dash were not included in that specific model. 
where $\mathbf{A}_{22}$ and $\mathbf{A}_{22}^{-1}$ are the pedigree relationship matrix and its inverse for genotyped animals only and $\mathbf{G}$ is the genomic relationship matrix based on SNP markers.

The constant $\lambda$ was used to avoid singularity problems. In this study, we used $\lambda=0.95$ for $\mathrm{NoO}_{\log }$ and $\lambda$ $=0.90$ for $\mathrm{NoM}_{\text {Ans }}$, because ASReml did not run with $\lambda=0.95$ for $\mathrm{NoM}_{\text {Ans }}$. The $\mathbf{H}^{-1}$ was calculated with the calc_grm software (Calus and Vandenplas, 2015), in which $\mathbf{G}$ was constructed using the method explained in VanRaden (2008).

\section{Cross-Validation}

A 10-fold cross-validation was carried out to examine the accuracy of pedigree-based and genomic-based EBV (EBV: pedigree based; GEBV: genomic based). The data set of genotyped animals with observations but without progeny was randomly split into 10 subsets. One subset was used as a validation data set, and for this data set the observations were masked and predicted to mimic the situation that the animal itself would not have a phenotype yet and no progeny (e.g., a newborn calf). The remaining 9 subsets and animals that were not included in the validation subsets were used as training set. Because animals in the training sets had different numbers of repeated observations for $\mathrm{NoO}_{\log }$ and $\mathrm{NoM}_{\text {Ans }}$, we used a mixed model to estimate the accuracy $\left(\mathrm{r}_{\mathrm{IH}}\right)$ by regressing phenotypes on the EBV or GEBV. Because a mixed model does not directly give the accuracy of EBV or GEBV, the $\mathrm{r}_{\mathrm{IH}}$ was derived from the estimated regression coefficient $\beta_{(\mathrm{G}) \mathrm{EBV}}$ using the definitions of the regression coefficient $\left(\beta_{(\mathrm{G}) \mathrm{EBV}}=\frac{\operatorname{cov}[(\mathrm{G}) \mathrm{EBV}, \mathrm{P}]}{\sigma_{(\mathrm{G}) \mathrm{EBV}}^{2}}\right)$ and of the correlation between $(\mathrm{G})$ EBV and phenotype $\left(\mathrm{r}=\frac{\operatorname{cov}[(\mathrm{G}) \mathrm{EBV}, \mathrm{P}]}{\sqrt{\sigma_{(\mathrm{G}) \mathrm{EBV}}^{2} \times \sigma_{\mathrm{P}}^{2}}}\right)$. After some algebraic manipulations, it can be shown that $\mathrm{r}=\frac{\beta_{(\mathrm{G}) \mathrm{EBV}} \times \sigma_{(\mathrm{G}) \mathrm{EBV}}}{\sigma_{\mathrm{p}}}$ and $\mathrm{r}_{\mathrm{IH}}=\frac{\mathrm{r}}{\sqrt{\mathrm{h}^{2}}}$, where $\sigma_{(\mathrm{G}) \mathrm{EBV}}$ is the standard deviation of EBV or GEBV, $\sigma_{\mathrm{p}}$ is the standard deviation of the phenotypes with $\sigma_{\mathrm{p}}=\sqrt{\sigma_{\mathrm{a}}^{2}+\sigma_{\mathrm{PE}}^{2}+\sigma_{\mathrm{e}}^{2}}$, and $\mathrm{h}^{2}$ is the heritability $\left(\mathrm{h}^{2}=\sigma_{\mathrm{a}}^{2} / \sigma_{\mathrm{P}}^{2}\right)$. To estimate $\beta_{(\mathrm{G}) \mathrm{EBV}}$, an univariate analysis was performed with the reduced model $\mathbf{y}=\mathbf{X} \boldsymbol{\beta}+$ $\mathbf{W} \mathbf{p}+\mathbf{e}$, where $\mathbf{y}$ is a vector for $\mathrm{NoO}_{\log }$ or $\mathrm{NoM}_{\text {Ans }}, \mathbf{X}$ and $\mathbf{W}$ are incidence matrices, $\boldsymbol{\beta}$ is a vector for fixed effects (Table 2) and the regression on the $(\mathrm{G}) \mathrm{EBV}, \mathbf{p}$ is a vector of permanent environmental effects, and $\mathbf{e}$ is a vector of random residuals.

\section{RESULTS}

\section{Descriptive Statistics, Variance Components, and Heritability}

The descriptive statistics of $\mathrm{NoO}, \mathrm{NoO}_{\log }$, NoM, and $\mathrm{NoM}_{\text {Ans }}$ are shown in Table 1. The mean NoO is 7.72 and the mean NoM is 9.27. Both traits have a wide range of values. Estimated variance components, heritabilities, and repeatabilities are presented in Table 3. A lower heritability was found for $\mathrm{NoM}_{\text {Ans }}(0.206 \pm$ $0.014)$ compared with $\mathrm{NoO}_{\log }(0.315 \pm 0.029)$. Adding genomic information to the pedigree information hardly affected the estimates of heritability $\left(\mathrm{NoM}_{\mathrm{Ans}}\right.$ : $\left.0.219 \pm 0.013 ; \mathrm{NoO}_{\mathrm{log}}: 0.309 \pm 0.026\right)$. Standard errors of heritability estimates were slightly smaller, with ssGBLUP showing slightly higher precision when using genomic information.

\section{Cross-Validation}

The accuracies estimated with cross-validation for animals with masked phenotypes mimicking young animals without phenotypes are presented in Table 3 . The accuracy of the EBV for $\mathrm{NoO}_{\log }$ was almost equal to the accuracy of $\mathrm{NoM}_{\text {Ans }}$, despite the lower heritability. Regression coefficients were in all cases close to unity, indicating hardly any bias in $(\mathrm{G}) \mathrm{EBV}$. The accuracy increased when using ssGBLUP compared with conventional BLUP, showing some benefit of using genomic information. The moderate accuracies show that GEBV can be used to select potential bull dams for OPU, MOET, or both.

\section{DISCUSSION}

In this study variance components and breeding values were estimated for $\mathrm{NoO}_{\log }$ and $\mathrm{NoM}_{\text {Ans. }}$. Furthermore, a cross-validation was used to assess the accuracy of pedigree and genomic breeding values for $\mathrm{NoO}_{\log }$ and $\mathrm{NoM}_{\text {Ans }}$.

\section{Variance Components and Heritability}

The heritabilities found for $\mathrm{NoO}_{\log }(0.31)$ and No$\mathrm{M}_{\text {Ans }}(0.22)$ were in line with previous studies. Previous studies found a heritability of 0.25 for $\mathrm{NoO}$ or $\mathrm{NoO}_{\log }$, whereas heritability estimates between 0.17 and 0.23 were reported for NoM or $\mathrm{NoM}_{\text {Ans }}$ (König et al., 2007; Merton et al., 2009; Jaton et al., 2016). Transformed or untransformed data gave for both traits very similar heritabilities (results not shown). In general, the heritability for $\mathrm{NoO}$ or $\mathrm{NoO}_{\log }$ is higher than the heritability for NoM or $\mathrm{NoM}_{\text {Ans. }}$. As shown in Merton et al. (2009), 
the heritability for $\mathrm{NoO}$ was higher than the number of viable embryos at d 7 (0.25 and 0.21 , respectively). Comparing number of transferable embryos at $\mathrm{d} 7$ after OPU with number of viable embryos collected with MOET would probably give more similar heritabilities than NoO and NoM.

It was suggested that $\mathrm{NoO}$ and $\mathrm{NoM}$ share the same biological background [i.e., number of ova in the ovary (Merton et al., 2009)]. Therefore, a high correlation between the traits is expected (Merton et al., 2009). As shown in Figure 1a, the $\mathrm{R}^{2}$ between NoO and NoM is 0.15 , resulting in a phenotypic correlation between $\mathrm{NoO}$ and NoM of 0.39 . The correlation between EBV of $\mathrm{NoO}_{\log }$ and $\mathrm{NoM}_{\text {Ans }}$ was even higher, namely $0.59\left(\mathrm{R}^{2}=\right.$ 0.35; Figure 1b), suggesting a high genetic correlation. Note that a correlation between EBV underestimates the genetic correlation due to lower than unity accuracies of EBV.

\section{Cross-Validation}

The mixed-model method used for cross-validation was also described by Bergsma et al. (2008), where heritable social effects were estimated in pigs. For reasons of comparison, we calculated the accuracy with a more common method using the correlation between (G)EBV and phenotypes corrected for fixed effects:

$$
\mathrm{r}=\frac{\operatorname{corr}[(\mathrm{G}) \mathrm{EBV}, \mathrm{Y}]}{\sqrt{\mathrm{h}^{2}}},
$$

where $r$ is the accuracy of estimation, corr $[(G) E B V, Y]$ is the correlation between the $(\mathrm{G}) \mathrm{EBV}$ and trait phenotypes corrected for fixed effects $(\mathrm{Y})$, and $\mathrm{h}^{2}$ is the heritability (Legarra et al., 2008). The correlation method described by Legarra et al. (2008) gave slightly lower accuracies for $\mathrm{NoO}_{\mathrm{log}}, 0.41$ for $\mathrm{EBV}$, and 0.49 for GEBV, whereas accuracies were 0.46 for EBV and 0.54 for GEBV when using the mixed model method described by Bergsma et al. (2008). The mixed model method is more suitable to deal with repeated observations in the data and statistically more appropriate, because permanent environmental effects can be included in the mixed model. The correlation method (Legarra et al., 2008; Verbyla et al., 2009) is very suitable when having a single observation per animal, but may give biased accuracies with repeated observations. Therefore, we believe that the mixed model method is statistically more appropriate for repeated observations.

The accuracies found for $\mathrm{NoO}_{\log }$ and $\mathrm{NoM}_{\text {Ans }}$ were almost equal, despite a lower heritability for NoM. The very similar accuracy was likely due to a difference in data structure. For NoM, sires had on average 9.15 offspring with observations, whereas for NoO, sires had on average 5.46 offspring with observations. Furthermore, NoM had more animals with data.

\section{Using Breeding Values for NoO and NoM in Breeding Schemes}

The success of breeding schemes partially depends on the number of progeny per selected donor used in

Table 3. Variance components, heritabilities, and accuracies of EBV or genomic EBV (GEBV) for logtransformed number of oocytes $\left(\mathrm{NoO}_{\mathrm{log}}\right)$ and Anscombe-transformed number of multiple ovulation and embryo transfer embryos $\left(\mathrm{NoM}_{\mathrm{Ans}}\right)$ using either only pedigree information or the single-step genomic BLUP method (ssGBLUP)

\begin{tabular}{|c|c|c|c|c|}
\hline \multirow{2}{*}{$\begin{array}{l}\text { Variance } \\
\text { component }\end{array}$} & \multicolumn{2}{|c|}{$\mathrm{NoO}_{\log }$} & \multicolumn{2}{|c|}{$\mathrm{NoM}_{\text {Ans }}$} \\
\hline & Pedigree & ssGBLUP & Pedigree & ssGBLUP \\
\hline$\sigma_{\mathrm{a}}^{2}$ & 0.021 & 0.020 & 0.277 & 0.299 \\
\hline$\sigma_{\mathrm{PE}}^{2}$ & 0.011 & 0.012 & 0.153 & 0.152 \\
\hline$\sigma_{\mathrm{e}}^{2}$ & 0.034 & 0.034 & 0.913 & 0.912 \\
\hline $\begin{array}{l}\mathrm{h}^{2}( \pm \mathrm{SE}) \\
\text { Repeatability }( \pm \mathrm{SE})\end{array}$ & $\begin{array}{l}0.315(0.029) \\
0.488(0.011)\end{array}$ & $\begin{array}{l}0.309(0.026) \\
0.489(0.011)\end{array}$ & $\begin{array}{l}0.206(0.014) \\
0.320(0.008)\end{array}$ & $\begin{array}{l}0.219(0.013) \\
0.331(0.008)\end{array}$ \\
\hline $\begin{array}{l}\text { Cross-validation } \\
\sigma_{\mathrm{p}} \\
\sigma_{\mathrm{EBV}} \\
\beta_{(\mathrm{G}) \mathrm{EBV}}\end{array}$ & $\begin{array}{l}0.257 \\
0.063 \\
1.058\end{array}$ & $\begin{array}{l}0.257 \\
0.076 \\
1.023\end{array}$ & $\begin{array}{l}1.159 \\
0.242 \\
0.977\end{array}$ & $\begin{array}{l}1.168 \\
0.287 \\
0.995\end{array}$ \\
\hline $\begin{array}{l}\mathrm{r}_{\mathrm{IH}} \\
\mathrm{r}_{\mathrm{IH}}^{2}\end{array}$ & $\begin{array}{l}0.464 \\
0.215\end{array}$ & $\begin{array}{l}0.544 \\
0.296\end{array}$ & $\begin{array}{l}0.456 \\
0.208\end{array}$ & $\begin{array}{l}0.522 \\
0.273\end{array}$ \\
\hline
\end{tabular}


MOET or OPU schemes. Therefore, accurate (G)EBV for MOET and OPU traits are of high value. Because (G)EBV were on the transformed scales, back transformation was needed to get an impression of the possibilities of selection on higher NoO or NoM. Selection differentials were calculated for both $\mathrm{NoO}$ and NoM comparing the best $10 \%$ animals with average animals based on GEBV (see Appendix for details). For NoO, the best $10 \%$ animals were expected to have 10.33 oocytes per OPU session, whereas the expectation for average animals was 7.65 oocytes. This is an increase of 2.68 oocytes per OPU session for $\mathrm{NoO}$, in other words, an increase of $35 \%$ in OPU efficiency compared with no selection on EBV for $\mathrm{NoO}_{\mathrm{log}}$. For NoM, the best $10 \%$ animals were expected to have 12.11 embryos per

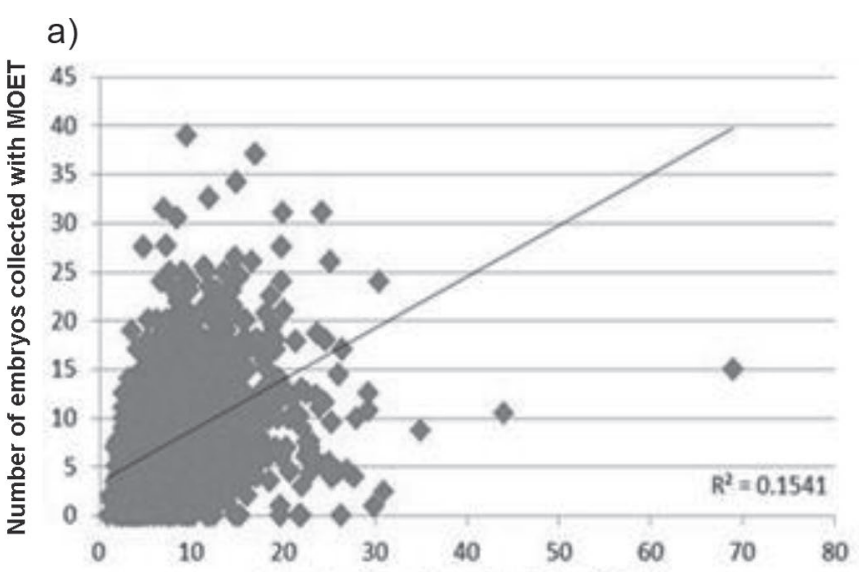

b)

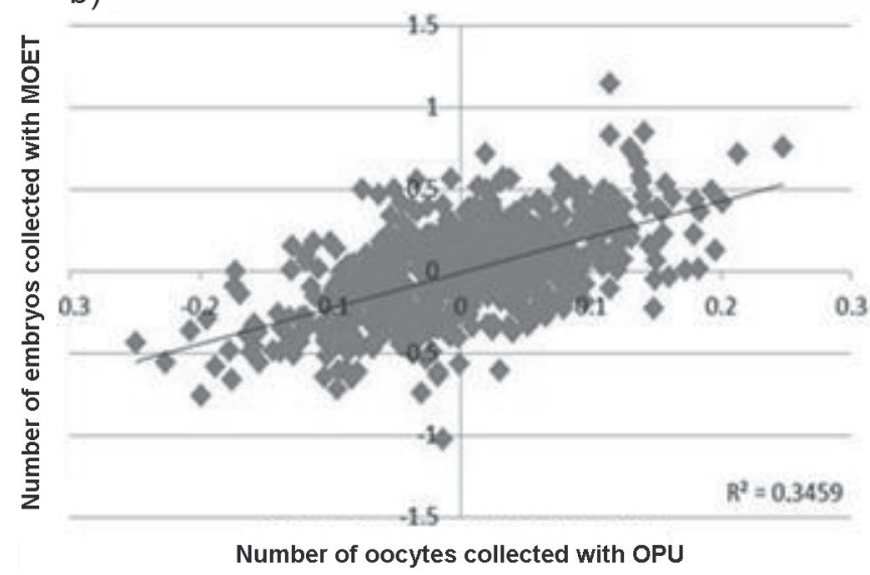

Figure 1. Relation between the phenotypic values and EBV for number of oocytes collected with ovum pick-up (OPU) and number of embryos collected with multiple ovulation and embryo transfer (MOET). (a) Relation of untransformed data between the phenotypic values for number of oocytes collected with OPU and number of embryos collected with MOET. (b) Relation of transformed data between the EBV for number of oocytes collected with OPU and EBV for number of embryos collected with MOET.
MOET session, whereas the expectation for average animals was 9.23 embryos. This is an increase of 2.88 embryos with MOET, in other words, an increase of $31 \%$ in MOET efficiency compared with no selection on EBV for $\mathrm{NoM}_{\text {Ans. }}$. These results show substantial genetic variation in $\mathrm{NoO}$ and NoM that can be used by selecting potential bull dams on GEBV. Note that the expectations for average animals were close to the average $\mathrm{NoO}$ and NoM in Table 1, but not the same due to using the average on the transformed scales in the calculations.

A second purpose of using GEBV for $\mathrm{NoO}$ and NoM is to validate the OPU and MOET processes. The OPU and MOET sessions vary greatly in NoO or NoM, which might be partly due to genetic differences between animals. Therefore, using the GEBV in analyzing NoO may help to explain some of the large variation observed and help in further optimizing protocols for OPU or MOET.

In short, we found moderate accuracies of GEBV for NoO and NoM. These GEBV can be used in the decision-making process when selecting elite donors for OPU and MOET programs. The GEBV for NoO and NoM can be used to further optimize dairy breeding schemes.

\section{ACKNOWLEDGMENTS}

CRV BV (Arnhem, the Netherlands) is acknowledged for financial support to Marit Cornelissen and for providing the data.

\section{REFERENCES}

Aguilar, I., I. Misztal, D. L. Johnson, A. Legarra, S. Tsuruta, and T. J. Lawlor. 2010. Hot topic: A unified approach to utilize phenotypic, full pedigree, and genomic information for genetic evaluation of Holstein final score. J. Dairy Sci. 93:743-752. https://doi. org/10.3168/jds.2009-2730.

Anscombe, F. J. 1948. The transformation of poisson, binomial and negative-binomial data. Biometrika 35:246-254. https://doi. org/10.2307/2332343.

Bergsma, R., E. Kanis, E. F. Knol, and P. Bijma. 2008. The contribution of social effects to heritable variation in finishing traits of domestic pigs (Sus scrofa). Genetics 178:1559-1570. https://doi. org/10.1534/genetics.107.084236.

Betteridge, K. J. 2003. A history of farm animal embryo transfer and some associated techniques. Anim. Reprod. Sci. 79:203-244. https://doi.org/10.1016/S0378-4320(03)00166-0.

Browning, S. R., and B. L. Browning. 2007. Rapid and accurate haplotype phasing and missing-data inference for whole-genome association studies by use of localized haplotype clustering. Am. J. Hum. Genet. 81:1084-1097. https://doi.org/10.1086/521987.

Calus, M. P. L., and J. Vandenplas. 2015. Calc_GRM-A program to compute pedigree, genomic, and combined relationship matrices. ABGC, Wageningen UR Livestock Research, the Netherlands.

Christensen, O. F., and M. S. Lund. 2010. Genomic prediction when some animals are not genotyped. Genet. Sel. Evol. 42:2. https:// doi.org/10.1186/1297-9686-42-2. 
Druet, T., and M. Georges. 2010. A hidden Markov model combining linkage and linkage disequilibrium information for haplotype reconstruction and quantitative trait locus fine mapping. Genetics 184:789-798. https://doi.org/10.1534/genetics.109.108431.

Gilmour, A. R., B. J. Gogel, B. R. Cullis, and R. Thompson. 2009. ASReml user guide release 3.0. VSN Int. Ltd.

Hanenberg, E. H. A. T., and A. M. van Wagtendonk-de Leeuw. 1997. Comparison of 3,4 , or 7 day interval between oocyte collections for in vitro embryo production results. Theriogenology 47:158 https://doi.org/10.1016/S0093-691X(97)82285-6.

IETS. 2014. 2013 Statistics of embryo collection and transfer in domestic farm animals. Int. Embryo Transf. Soc. 2:1-13.

Jaton, C., A. Koeck, M. Sargolzaei, F. Malchiodi, C. A. Price, F. S Schenkel, and F. Miglior. 2016. Genetic analysis of superovulatory response of Holstein cows in Canada. J. Dairy Sci. 99:3612-3623. https://doi.org/10.3168/jds.2015-10349.

König, S., F. Bosselmann, U. U. von Borstel, and H. Simianer. 2007. Genetic analysis of traits affecting the success of embryo transfer in dairy cattle. J. Dairy Sci. 90:3945-3954. https://doi.org/10.3168/ jds.2007-0089.

Legarra, A., C. Robert-Granie, E. Manfredi, and J.-M. Elsen. 2008. Performance of genomic selection in mice. Genetics 180:611-618. https://doi.org/10.1534/genetics.108.088575.

Merton, J. S., B. Ask, D. C. Onkundi, E. Mullaart, B. Colenbrander, and M. Nielen. 2009. Genetic parameters for oocyte number and embryo production within a bovine ovum pick-up in vitro production embryo-production program. Theriogenology 72:885-893. https://doi.org/10.1016/j.theriogenology.2009.06.003.

Merton, J. S., A. P. W. De Roos, E. Mullaart, L. De Ruigh, L. Kaal, P. L. A. M. Vos, and S. J. Dieleman. 2003. Factors affecting oocyte quality and quantity in commercial application of embryo technologies in the cattle breeding industry. Theriogenology 59:651-674. https://doi.org/10.1016/S0093-691X(02)01246-3.

Mulder, H. A., M. P. L. Calus, T. Druet, and C. Schrooten. 2012. Imputation of genotypes with low-density chips and its effect on reliability of direct genomic values in Dutch Holstein cattle. J. Dairy Sci. 95:876-889. https://doi.org/10.3168/jds.2011-4490.

Pieterse, M. C., K. A. Kappen, T. A. M. Kruip, and M. A. M. Taverne. 1988. Aspiration of bovine oocytes during transvaginal ultrasound scanning of the ovaries. Theriogenology 30:751-762. https://doi. org/10.1016/0093-691X(88)90310-X.

Schaeffer, L. R. 2006. Strategy for applying genome-wide selection in dairy cattle. J. Anim. Breed. Genet. 123:218-223. https://doi. org/10.1111/j.1439-0388.2006.00595.x.

SPSS Inc. 2007. SPSS for Windows, Version 16.0. SPSS Inc., Chicago, IL.

van Wagtendonk-de Leeuw, A. M. 2006. Ovum pick up and in vitro production in the bovine after use in several generations: A 2005 status. Theriogenology 65:914-925. https://doi.org/10.1016/j. theriogenology.2005.09.007.

VanRaden, P. M. 2008. Efficient methods to compute genomic predictions. J. Dairy Sci. 91:4414-4423. https://doi.org/10.3168/ jds.2007-0980

Verbyla, K. L., B. J. Hayes, P. J. Bowman, and M. E. Goddard. 2009. Accuracy of genomic selection using stochastic search variable selection in Australian Holstein Friesian dairy cattle. Genet. Res. (Camb.) 91:307. https://doi.org/10.1017/S0016672309990243.

\section{APPENDIX}

\section{Back Transforming (G)EBV from Transformed to Observed Scale and Calculating Selection Differentials}

We used an Anscombe or square root transformation for $\mathrm{NoM}\left(\mathrm{NoM}_{\mathrm{Ans}}\right)$ and a log-transformation for $\mathrm{NoO}$ $\left(\mathrm{NoO}_{\log }\right)$. The $(\mathrm{G}) \mathrm{EBV}$ obtained were therefore on the transformed scale, and back transformation was needed to interpret them on the observed scale. For the square root transformation, we squared the response variable. For simplicity in the derivations, we assumed the simplest genetic model with a breeding value (A) and an environmental or residual effect (E), both normally distributed on the square root scale:

$$
\begin{gathered}
\sqrt{\mathrm{P}+\frac{3}{8}}=\mu+\mathrm{A}+\mathrm{E}, \\
\mathrm{P}+\frac{3}{8}=(\mu+\mathrm{A}+\mathrm{E})^{2}=\mu^{2}+\mathrm{A}^{2}+\mathrm{E}^{2}+2 \mu \mathrm{A}+2 \mu \mathrm{E}+2 \mathrm{AE},
\end{gathered}
$$

where $\mathrm{P}$ is the phenotype and $\mu$ is the overall mean. Using the properties of a normal distribution, $\mathrm{E}\left(\mathrm{A}^{2}\right)=\sigma_{\mathrm{A}}^{2}$, $\mathrm{E}\left(\mathrm{E}^{2}\right)=\sigma_{\mathrm{E}}^{2}, \mathrm{E}(2 A E)=0$, the expected phenotype given $\mathrm{A}$ is

$$
\mathrm{E}(\mathrm{P} \mid \mathrm{A})=\mu^{2}+\sigma_{\mathrm{A}}^{2}+\sigma_{\mathrm{E}}^{2}+2 \mu \mathrm{A}-\frac{3}{8} .
$$

Therefore, the (G)EBV was back transformed as

$$
\widehat{\mathrm{A}_{\mathrm{obs}}}=2 \mu \widehat{\mathrm{A}_{\mathrm{sqrt}}}
$$

where $\mathrm{A}_{\text {obs }}$ is the EBV on the observed scale and $\mathrm{A}_{\text {sqrt }}$ is the EBV on the square-root scale. For the log-transformation with base 10, the back transformation involved a power with base 10: 


$$
\begin{gathered}
\log _{10}(\mathrm{P}+1)=\mu+\mathrm{A}+\mathrm{E}, \\
\mathrm{P}+1=10^{\mu+\mathrm{A}+\mathrm{E}} .
\end{gathered}
$$

The expected deviation from the average phenotype given A was calculated as (exact)

$$
\mathrm{E}(\mathrm{P}-\mu \mid \mathrm{A})=10^{\mu+\mathrm{A}}-10^{\mu} .
$$

Therefore, the (G)EBV was back transformed as

$$
\widehat{A_{\mathrm{obs}}}=10^{\mu+\widehat{A_{\log }}}-10^{\mu} .
$$

The expected phenotype given A was derived using a second-order Taylor series approximation at $\mu$ :

$$
\begin{array}{r}
\mathrm{E}(\mathrm{P} \mid \mathrm{A})=10^{\mu}-1+\left(\sigma_{\mathrm{A}}^{2}+\sigma_{\mathrm{E}}^{2}\right) \times 0.5[\ln (10)]^{2} \times \exp [\mu \ln (10)] \\
+\mathrm{A} \times \ln (10) \times \exp [\mu \ln (10)]+\mathrm{A}^{2} \times 0.5[\ln (10)]^{2} \times \exp [\mu \ln (10)] .
\end{array}
$$

The selection differentials, for instance, when selecting the best $10 \%$ of animals on GEBV, were calculated on the transformed scale as

$$
\Delta \mathrm{A}=\mathrm{ir}_{\mathrm{IH}} \sigma_{\mathrm{a}},
$$

where $\mathrm{i}$ is the selection intensity, $\mathrm{r}_{\mathrm{IH}}$ is the accuracy of the GEBV (Table 3), and $\sigma_{\mathrm{a}}$ is the genetic standard deviation (Table 3). The expected phenotypic selection differentials for these genetic selection differentials were calculated using Equation [A4] for NoM and Equation [A7] for NoO:

$$
\begin{gathered}
\Delta \mathrm{P}_{\mathrm{NoM}}=2 \mu \Delta \mathrm{A}, \\
\Delta \mathrm{P}_{\mathrm{NoO}}=10^{\mu+\Delta \mathrm{A}}-10^{\mu} .
\end{gathered}
$$

